\title{
Postembryonic Developmental Changes in Photoreceptors of the Stick Insect Carausius morosus Enhance the Shift to an Adult Nocturnal Life-Style
}

\author{
Roman Frolov, Esa-Ville Immonen, Mikko Vähäsöyrinki, and Matti Weckström \\ Department of Physics, Division of Biophysics, University of Oulu, Oulun yliopisto, Finland
}

\begin{abstract}
Optimization of sensory processing during development can be studied by using photoreceptors of hemimetabolous insects (with incomplete metamorphosis) as a research model. We have addressed this topic in the stick insect Carausius morosus, where retinal growth after hatching is accompanied by a diurnal-to-nocturnal shift in behavior, by recording from photoreceptors of first instar nymphs and adult animals using the patch-clamp method. In the nymphs, ommatidia were smaller and photoreceptors were on average 15-fold less sensitive to light than in adults. The magnitude of A-type $\mathrm{K}^{+}$current did not increase but the delayed rectifier doubled in adults compared with nymphs, the $\mathrm{K}^{+}$current densities being greater in the nymphs. By contrast, the density of light-induced current did not increase, although its magnitude increased 8.6-fold, probably due to the growth of microvilli. Nymph photoreceptors performed poorly, demonstrating a peak information rate (IR) of $2.9 \pm 0.7 \mathrm{bits} / \mathrm{s}$ versus $34.1 \pm 5.0 \mathrm{bits} / \mathrm{s}$ in adults in response to white-noise stimulation. Strong correlations were found between photoreceptor capacitance (a proxy for cell size) and IR, and between light sensitivity and IR, with larger and more sensitive photoreceptors performing better. In adults, IR peaked at light intensities matching irradiation from the evening sky. Our results indicate that biophysical properties of photoreceptors at each age stage and visual behavior are interdependent and that developmental improvement in photoreceptor performance may facilitate the switch from the diurnal to the safer nocturnal lifestyle. This also has implications for how photoreceptors achieve optimal performance.
\end{abstract}

\section{Introduction}

Natural selection leads to some kind of optimal tuning of sensory systems to an animal's habitat (Machens et al., 2005; Porter et al., 2010; Warrant and Dacke, 2011). Optimal performance is usually achieved when a sensory system becomes developmentally mature, whereas for the young this may constitute a problem and require behavioral modifications during rapid growth in the same ecological niche as the adult. Much has been published on various morphological, physiological and behavioral adaptations of organisms to environment, and on the changes in these adaptations over the course of individual development. However, little is known about mechanisms underlying the interplay between developmental changes in sensory function and concomitant changes in related behaviors, partly due to experimental difficulties.

Some novel insights into optimal tuning of photoreceptors can be gained from examination of postembryonic development in certain species of the hemimetabolous insects (those with in-

\footnotetext{
Received May 30, 2012; revised Sept. 11, 2012; accepted Sept. 21, 2012.

Author contributions: R.F. designed research; R.F. performed research; R.F. and E.-V.I. analyzed data; R.F., E.-V.I., M.V., and M.W. wrote the paper.

This study was supported by grants from the Academy of Finland to R.F., M.V., and M.W. and from the FGSN to E.-V.I. We thank Jouni Takalo for help with information rate calculations and Dr. Jeremy Niven for valuable comments on the manuscript.

The authors declare no competing financial interests.

Correspondence should be addressed to Roman Frolov, Department of Physics, Division of Biophysics, University of Oulu, PO Box 3000, 90014 Oulun yliopisto, Finland. E-mail: rvfrolov@gmail.com.

DOI:10.1523/JNEUROSCI.2612-12.2012

Copyright $\odot 2012$ the authors $\quad 0270-6474 / 12 / 3216821-11 \$ 15.00 / 0$
}

complete metamorphosis). These animals are characterized by continuous postembryonic development, proceeding through a series of instar molts before the final molt to an adult. Nymphs often share the same habitat with adults, but may display differences in behavior. While such differences cannot be traced to a single sensory system, developmental changes in the day-night activity preferences have been previously associated with postembryonic growth of the compound eye (Meyer-Rochow and Keskinen, 2003). Early instars of such species are active during day or prefer better-lit backgrounds, whereas the adults are crepuscular or nocturnal, or prefer dimmer environments than the nymphs (Tomioka and Chiba, 1982; Keskinen et al., 2002; Meyer-Rochow and Keskinen, 2003). Although numerous factors are likely to be at play in determining the diurnal behavior of the nymphs, the simplest explanation could be that the visual systems of visually guided young are inadequate for vision in dim light, forcing animals to be day-active.

In this work we studied developmental changes in biophysical properties of photoreceptors of the stick insect Carausius morosus in the context of developmental changes in behavior. Newly emerged small first instar nymphs are diurnal feeders, freely moving around; they possess small compound eyes with $<300$ facets in each. With each consecutive moult, the eyes grow and after the last moult the number of ommatidia in the adult eye exceeds 600; by that stage, stick insects are nocturnal; they feed during night and cling to their foodplants during the day, assuming an immobile stick posture. Morphological changes in the retina are profound and include severalfold increases in thickness of the retinal layer, and in the ommatidial and rhabdom 
diameters (Meyer-Rochow and Keskinen, 2003). These changes occur uniformly with growth and can be assumed to be accompanied by similarly continuous alterations in the electrical properties of photoreceptors. We recorded from dissociated ommatidia of the diurnal first instar and nocturnal adult stick insects-the two stages most different in respect to compound eye anatomy and animal behavior. A number of differences in biophysical properties of photoreceptors were found. Our results indicate that photoreceptor function at each stage is developmentally adapted to the preferred illumination background.

\section{Materials and Methods}

Electrophysiology. Indian stick insects (females, reproducing through parthenogenesis) were purchased from Blades Biological and maintained at room temperature under normal $12 \mathrm{~h}$ illumination conditions. Ommatidia were dissociated as described previously (Krause et al., 2008). Whole-cell recordings from dissociated ommatidia and data analysis were performed at room temperature as described previously (Hardie et al., 1991; Krause et al., 2008). In brief, Sensapex micromanipulators, an Axopatch 1-D patch-clamp amplifier and pClamp 9.2 software (Molecular Devices) were used for data acquisition and analysis. Patch electrodes were fabricated from thin-walled borosilicate glass (World Precision Instruments). Electrodes had a resistance of 3.0-8.0 $\mathrm{M} \Omega$. Bath solution contained the following (in $\mathrm{mM}$ ): 120 $\mathrm{NaCl}, 5 \mathrm{KCl}, 4 \mathrm{MgCl}_{2}, 1.5 \mathrm{CaCl}_{2}, 10 \mathrm{~N}$-Tris(hydroxymethyl)-methyl-2-amino-ethanesulfonic acid (TES), 25 proline and 5 alanine, $\mathrm{pH}$ 7.15. Patch pipette solution contained the following (in mM): $140 \mathrm{KCl}, 10 \mathrm{TES}, 2 \mathrm{MgCl}_{2}, 4 \mathrm{Mg}$-ATP, $0.4 \mathrm{Na}-\mathrm{GTP}$ and $1 \mathrm{NAD}, \mathrm{pH}$ 7.15. All chemicals were purchased from Sigma-Aldrich Inc.. The liquid junction potential (LJP) between bath and intracellular solution was $-4 \mathrm{mV}$. All voltage values cited in text were corrected for the LJP. The series resistance was compensated by $80 \%$ and after compensation was typically lower than $8 \mathrm{M} \Omega$. Membrane capacitance was calculated from the total charge flowing during capacitive transients for voltage steps from -104 to -84 or $-74 \mathrm{mV}$.

For light stimulation, a computer-controlled custom-made voltageto-current driver for light-emitting diodes (LEDs) was used. Ten monochromatic LEDs (Roithner Laser Technik), covering a range from 355 to $639 \mathrm{~nm}$, were used in combination with a series of neutral density filters (ranging from 0 to $8 \mathrm{log}$ units of attenuation; Kodak). Spectrometer USB4000 (Ocean Optics) was used to measure light intensity. To compare environmental light intensity with the intensity of green light stimulation, the intensity of ambient light reflected from a green card was measured at different times of day using Model 350 Optometer (United Detector Technology). Intensity of the experimental light source was measured at the objective covered by a glass coverslip (which is used to make the bottom of the recording chamber), corrected for the effective diameter of objective and then compared with the readings of environmental illumination.

Data analysis. To measure photoreceptor performance, a computer generated $60 \mathrm{~s}$ light contrast series, made of 30 repetitions of a $2 \mathrm{~s}$ Gaussian randomly modulated (white-noise) sequence and a $60 \mathrm{~s}$ naturalistic contrast sequence from the van Hateren natural image database were used (van Hateren and van der Schaaf, 1998). The white-noise sequence had a mean contrast of 0.31 and a $3 \mathrm{~dB}$ cutoff ("corner") frequency of 250 $\mathrm{Hz}$. Photoreceptor performance was examined in the frequency domain using Matlab (MathWorks) as described previously (Kouvalainen et al., 1994; Faivre and Juusola, 2008). The analysis of responses to white noisemodulated light was performed by estimating the $2 \mathrm{~s}$ signal $S(\mathrm{f})$ by averaging voltage responses to 30 repetitions of a $2 \mathrm{~s}$ white-noise sequence. The noise was then obtained by subtracting the signal estimate from the original (noise-containing) sequences. The signal-to-noise ratio $(\operatorname{SNR}(\mathrm{f}))$ was obtained in the frequency domain as $\operatorname{SNR}(\mathrm{f})=|S(\mathrm{f})|^{2} /$ $|N(\mathrm{f})|^{2}$, where $|S(\mathrm{f})|^{2}$ is the estimated response signal power spectrum and $|N(\mathrm{f})|^{2}$ is the estimated noise power spectrum. The contrast gain of voltage responses $|T(\mathrm{f})|$ was calculated by dividing the cross-spectrum of photoreceptor input (white-noise contrast, $C(\mathrm{f})$ ) and output (photoreceptor signal) $S(\mathrm{f}) \cdot C^{*}(\mathrm{f})$ (the asterisk denoting the complex conjugate), by the autospectrum of the input $C(\mathrm{f}) \cdot C^{\star}(\mathrm{f})$ and taking the absolute value of the resulting frequency response function $T(\mathrm{f}): T(\mathrm{f})=$ $S(\mathrm{f}) \cdot C^{\star}(\mathrm{f}) / C(\mathrm{f}) \cdot C^{\star}(\mathrm{f})$. The Shannon information rate (IR) for whitenoise modulated responses was calculated according to the equation $\mathrm{IR}=\int\left(\log _{2}[|S(\mathrm{f})| /|N(\mathrm{f})|+1]\right) \mathrm{df}$ within a frequency range from $1 \mathrm{~Hz}$ to a frequency where the value of SNR equaled 0.5 (usually $<15 \mathrm{~Hz}$ in nymphs and $<25 \mathrm{~Hz}$ in adults).

All values are given as mean \pm SEM unless stated otherwise. Statistical analysis was performed using a two sample $t$ test assuming unequal variances; significant at $p<0.05$ or $p<0.01$. Spearman's rank correlation coefficient was calculated as described previously (Myers and Well, 2003).

\section{Results}

\section{General properties}

Figure 1 demonstrates photographs of adult and first instar nymph stick insects (Fig. $1 A$ ), their eyes (Fig. $1 B, C$ ) and typical isolated ommatidia suitable for patch-clamp recordings (Fig. $1 D, E)$. Dissociated ommatidia lacked axons but otherwise ap- 

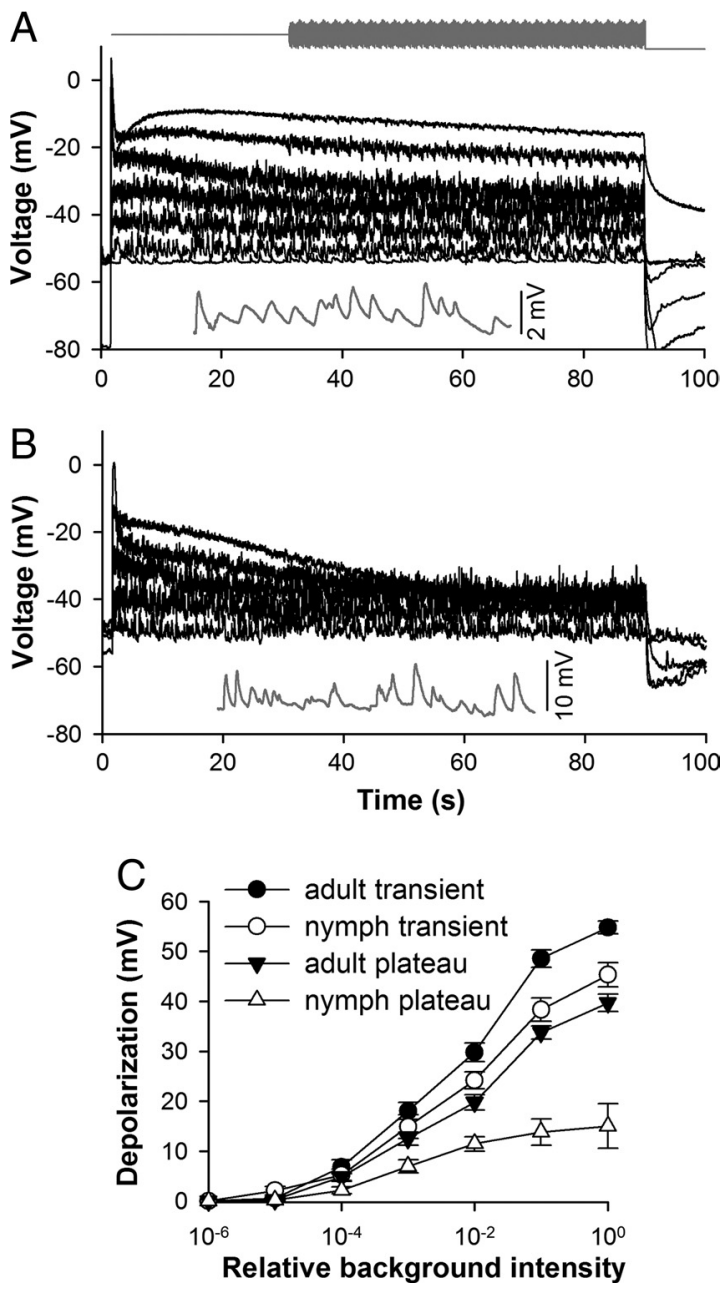

Figure2. Voltage responses to light of stick insect photoreceptors. Typical voltage responses of a photoreceptor from an adult $(\boldsymbol{A})$ and nymph $(\boldsymbol{B})$ to $90 \mathrm{~s}$ light pulses (30 s steady light followed by $60 \mathrm{~s}$ white-noise stimulation, gray inset trace) of increasing intensity in 10-fold increments; in this and following figures, an LED with maximum output at $525 \mathrm{~nm}$ was used for stimulation. Note that in $\boldsymbol{A}$ the brightest light elicits a prolonged depolarizing afterpotential (PDA). Insets in $\boldsymbol{A}$ and $\boldsymbol{B}$ demonstrate $4 \mathrm{~s}$ tracts of voltage responses to the dimmest stimulus in each panel with a rate of $\sim 4$ and 5 effective photons $s^{-1}$, respectively. C, Dependence of transient and steady-state depolarization on light intensity in nymphs and adults. Steady-state depolarization was determined as the difference between average potential from 30 to $90 \mathrm{~s}$ after onset of light and resting potential; 12 photoreceptors from adults and 9 cells from nymphs were used. Here and in all following figures error bars denote SE of measurement.

peared fully functional and robust, sometimes withstanding up to $30 \mathrm{~min}$ of electrical and light stimulation without deterioration of responses. The average resting potential was $-51.8 \pm 1.7 \mathrm{mV}$ in the nymphs ( 14 cells) and $-53.0 \pm 1.3 \mathrm{mV}$ in the adults (12 cells). Figure 2 shows representative light responses from nymph and adult photoreceptors. All photoreceptors except one had spectral sensitivity maxima between 490 and $525 \mathrm{~nm}$; in one case a UV-sensitive cell was recorded (Fig. $3 A$ ). The latter was not responsive to wavelengths $>435 \mathrm{~nm}$ but otherwise demonstrated typical electrical responses. Ommatidia from the nymphs were smaller than those from the adults. Whole-cell capacitance, a measure directly proportional to the membrane surface area, was used as a proxy for the size of photoreceptors. The average photoreceptor capacitance was $37 \pm 21 \mathrm{pF}$ (from 10 to $100 \mathrm{pF}$ ) in the nymphs (27 cells) and $212 \pm 104 \mathrm{pF}$ (from 54 to $500 \mathrm{pF}$ ) in the adults (31 cells, mean \pm SD), indicating a corresponding increase of total membrane area from $\sim 4 \cdot 10^{3}$ to $\sim 20 \cdot 10^{3} \mu \mathrm{m}^{2}$. Large
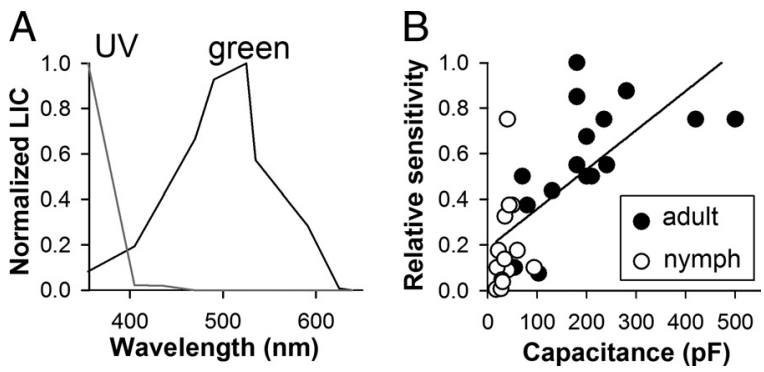

Figure 3. Photoreceptor sensitivity and capacitance. $\boldsymbol{A}$, Light-induced current responses to light of different wavelength of a UV-sensitive photoreceptor from a nymph, and of a typical green-sensitive photoreceptor from an adult; photoreceptors were stimulated by 20 ms flashes of different wavelength LEDs. The cells were held at a holding potential (HP) of $-74 \mathrm{mV}$; stimulus intensity for each LED was calculated to yield an equal number of incident photons per second. $\boldsymbol{B}$, Correlation between the photoreceptor capacitance and the relative sensitivity to light. The trend was illustrated by fitting data points with a linear function (in this and following figures, open circles, nymphs; closed circles, adults).

variation in photoreceptor capacitance at each developmental stage is consistent with the previously observed variation in stick insect ommatidial diameter, rhabdom diameter, and retinal thickness (Meyer-Rochow and Keskinen, 2003).

\section{Sensitivity to light}

Photoreceptor sensitivity was measured by counting bumps, the voltage responses to single photons, evoked by continuous stimulation at light intensities dim enough to elicit only $<10$ bumps $\mathrm{s}^{-1}$ to avoid overlapping bumps ( $<5$ bumps per second on average) (Fig. $2 A, B$, insets). For each photoreceptor, sensitivity to light was defined as the reciprocal of light intensity that would induce 1 effective photon $\mathrm{s}^{-1}$. The relative light sensitivity was then calculated as a fraction of sensitivity of the most sensitive cell in the experiments (Fig. 3B). Stick insect photoreceptors demonstrated large variation in light sensitivity both between and within the experimental groups of nymphs and adults. On average, photoreceptors from adult stick insects produced 1 effective photon $\mathrm{s}^{-1}$ at 15 -fold lower light intensity than the nymph photoreceptors. A strong correlation between sensitivity to light and capacitance was found (Fig. 3B). The Spearman's rank correlation coefficient $(\rho)$ was 0.89 , and $\rho^{2}$ was 0.80 , the value of $\rho^{2}$ reflecting the proportion of variation in the photoreceptor sensitivity, which can be explained by the variation in the photoreceptor capacitance. These results are consistent with the idea that the growth of photoreceptors during development takes place predominantly in the microvilli, increasing the membrane area available for absorbing light.

\section{Vision in dim light}

Adult stick insects are nocturnal animals, which presumably require a good ability to perceive and make sense of weak light signals. This requirement is usually associated with relatively large voltage responses to single photons or to dim light generally (Laughlin, 1996; Heimonen et al., 2006; Frederiksen et al., 2008). Insets in Figure 2, $A$ and $B$, demonstrate elementary voltage responses to continuous light at levels of 4 and 5 effective photons $\mathrm{s}^{-1}$, respectively. Figure $4 A$ shows typical voltage and current responses of an adult photoreceptor to a naturalistic light contrast. In this photoreceptor the stimulus (gray trace) elicited on average 6 effective photons per second. Clearly, both the lightinduced current (LIC) and photoreceptor's voltage response followed the stimulus, indicating that stick insects can see in dim light. 

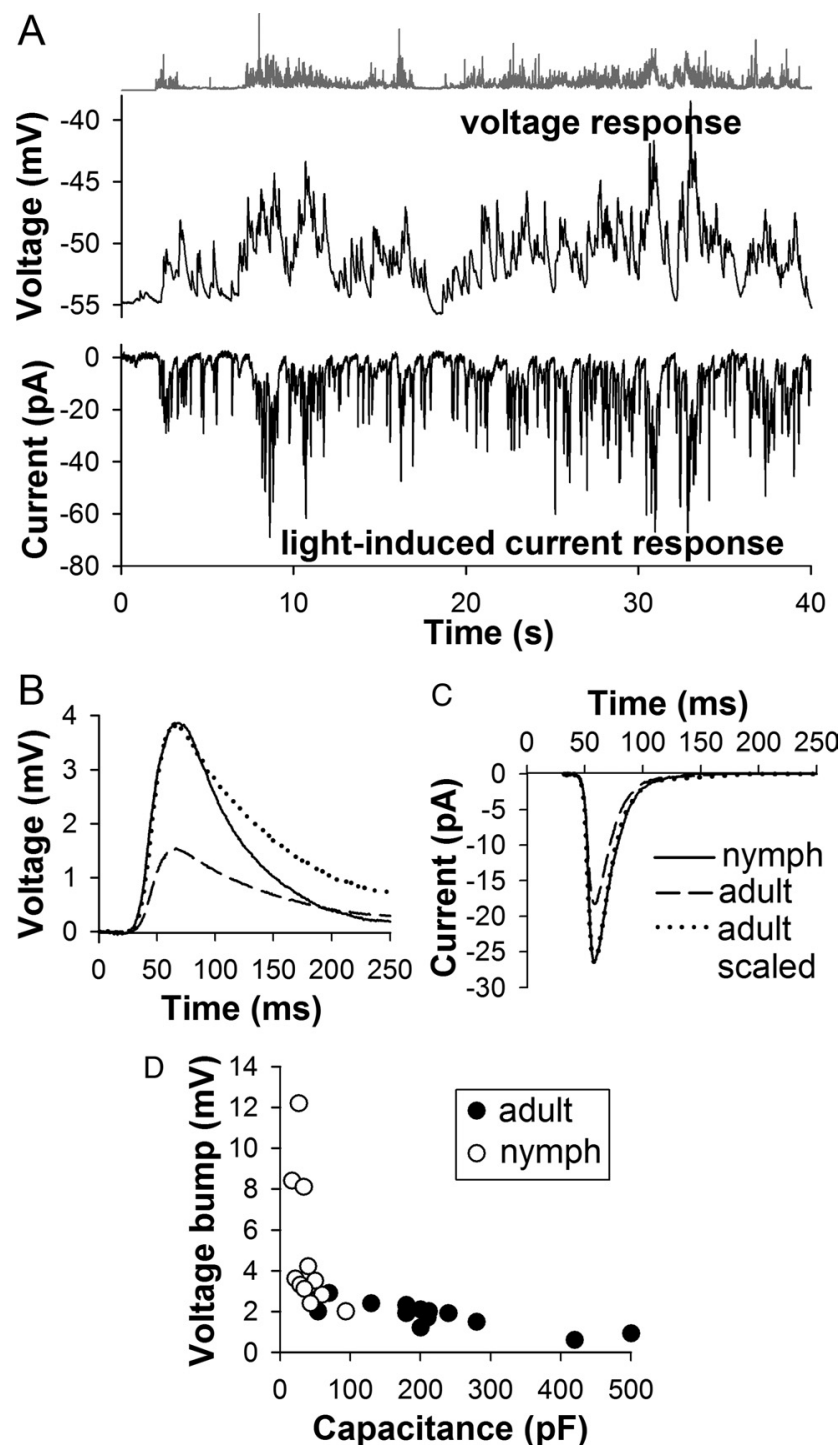

Figure 4. Responses in $\operatorname{dim}$ light. $\boldsymbol{A}$, Typical voltage and current responses of a stick insect photoreceptor to a naturalistic light contrast. In this adult photoreceptor, the stimulus (gray trace) elicited on average 6 effective photons $s^{-1}$ response. $\boldsymbol{B}, \boldsymbol{C}$, Representative average voltage $(\boldsymbol{B})$ and current $(\boldsymbol{C})$ bumps recorded from nymphs and adults. Voltage bumps were elicited by a steady light stimulus; current bumps were evoked by $1 \mathrm{~ms}$ light flashes at a holding potential (HP) of $-74 \mathrm{mV}$ (solid line, nymphs; short dash, adults; dotted line, scaled adults). $\boldsymbol{D}$, Dependence of average voltage bump amplitude on photoreceptor capacitance.

Stick insect photoreceptors produced large voltage quantum bumps (Fig. $4 A, B, D$ ). On average, voltage bumps were significantly bigger in the nymphs than in the adults: $5.1 \pm 1.0 \mathrm{mV}(12$ cells) versus $1.9 \pm 0.2 \mathrm{mV}$ ( 13 cells), respectively $(p<0.01)$ (Fig. $4 B$ ). In one cell, for example, the average voltage bump reached $12 \mathrm{mV}$, with individual bumps as high as $18 \mathrm{mV}$ (Fig. 4D). Voltage bump size depends on the amplitude of the current quantum bump, the cell's input resistance $\left(R_{\mathrm{in}}\right)$, and the membrane time constant. All these parameters facilitated larger voltage bumps in the nymphs. Current quantum bumps were larger in the nymphs, $26.9 \pm 3.4 \mathrm{pA}$ versus $19.1 \pm 1.7 \mathrm{pA}$ in the adults $(p<0.05)$ (Fig. $4 C) . R_{\text {in }}$ measured in the dark in voltage-clamp mode at $-54 \mathrm{mV}$ was $1390 \pm 170$ and $620 \pm 90 \mathrm{M} \Omega$ in the nymphs and adults, respectively. The cell membrane, when passive (i.e., without voltage-activated conductances) forms a low pass filter with a corner $(3 \mathrm{~dB})$ frequency $f_{3 \mathrm{~dB}}=1 /(2 \pi$ $\left.R_{\text {in }} C\right), R_{\text {in }}$ denoting the cell input resistance and $C$ the whole-cell

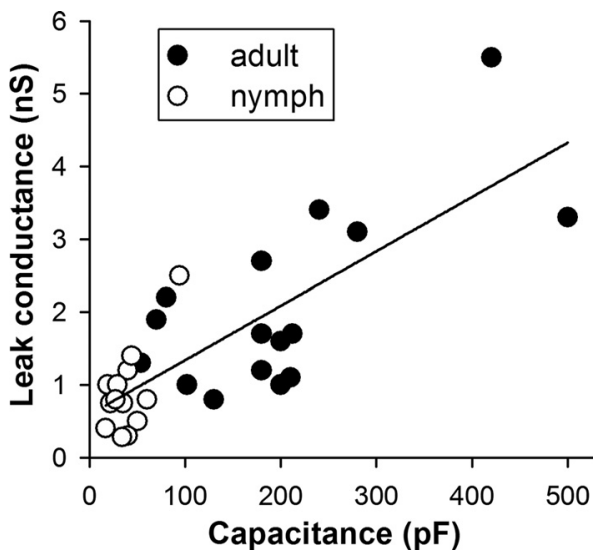

Figure 5. Correlation between the photoreceptor capacitance and leak conductance. Leak conductance values were obtained using 500 ms pulses between -64 and $-74 \mathrm{mV}$; data were fitted with a linear function.

capacitance. At $-54 \mathrm{mV}$, the calculated $f_{3 \mathrm{~dB}}$ was $4.0 \mathrm{~Hz}$ for nymph and $1.9 \mathrm{~Hz}$ for adult photoreceptors, the difference resulting predominantly from a 5.4-fold lower capacitance of nymph photoreceptors, despite their high input resistance. Higher corner frequency means that the membrane can transmit faster signals such as quantum bumps with less attenuation. A lower $f_{3 \mathrm{~dB}}$ of the adult photoreceptors was manifested in the slower decay kinetics of voltage bumps (Fig. $4 B$ ). Note the strong negative correlation between average voltage bump size and cell capacitance (Fig. $4 D, \rho=0.70, \rho^{2}=0.49$ ), suggesting that lower photoreceptor capacitance was the main factor facilitating large voltage bumps due to the greater $f_{3 \mathrm{~dB}}$, which filtered less fast and large current bumps. This is also consistent with the observation that developmental changes in capacitance were much greater than changes in two other relevant factors, $R_{\text {in }}$ and quantum bump size.

\section{Developmental changes in ionic currents}

In the dark, photoreceptor resistance is mainly determined by leak conductances and voltage-activated $\mathrm{K}^{+}$conductances. In our experimental setting, leak conductance consisted of the actual leak current and an unknown fraction of instrumental leak current through the membrane-electrode interface. The total leak conductance determined in the voltage-clamp mode between -64 and $-74 \mathrm{mV}$, where no voltage-activated currents could be detected, was $0.7 \pm 0.1 \mathrm{nS}$ in the nymphs and $1.6 \pm 0.3$ $\mathrm{nS}$ in the adults, and a strong correlation was found between photoreceptor capacitance and the magnitude of leak current (Fig. 5, $\rho=0.78, \rho^{2}=0.61$ ). This indicated a developmental increase in the physiological leak current as could be expected to occur with cell growth, if we assumed that the density of leak channels remains the same. Also, it implied a relatively small magnitude of the instrumental leak current, which did not mask the observed change. Note that because of the same experimental conditions the instrumental leak is likely to be very similar in both cases. In fact, as there was little correlation between capacitance and leak current among the nymphs, it is possible that leak current in that group was completely dominated by random instrumental leak current.

Voltage-activated $\mathrm{K}^{+}$channels expressed in photoreceptors modulate membrane resistance and, therefore, membrane filtering, in a voltage- and time-dependent manner. Two voltageactivated outward currents with hallmarks of a rapidly activating and inactivating A-type $\mathrm{K}^{+}$current $\left(I_{\mathrm{A}}\right)$ and a slowly inactivating 
A

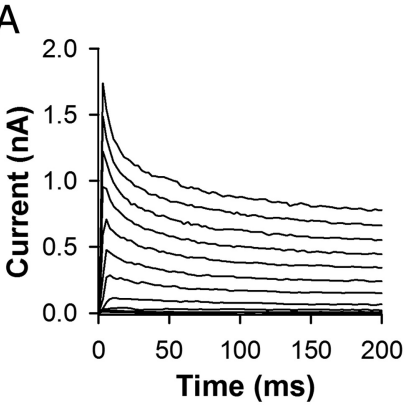

D - adult I $\mathrm{DR}_{\mathrm{D}}$
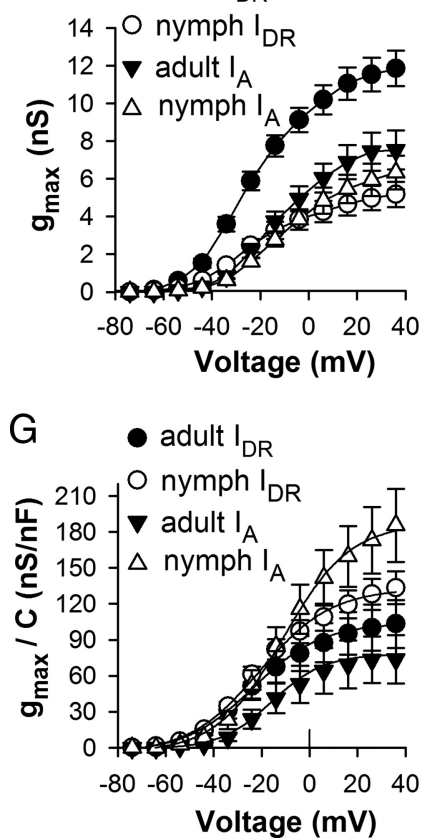

B

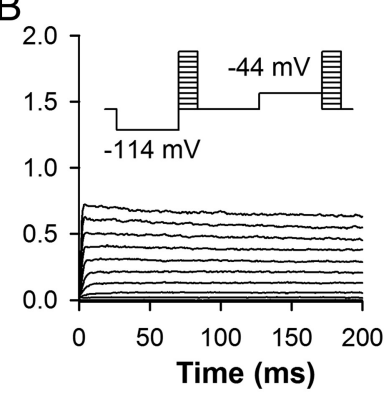

E

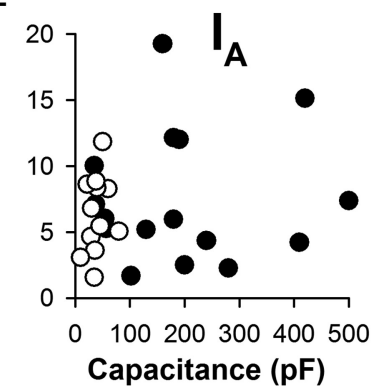

$\mathrm{H}$

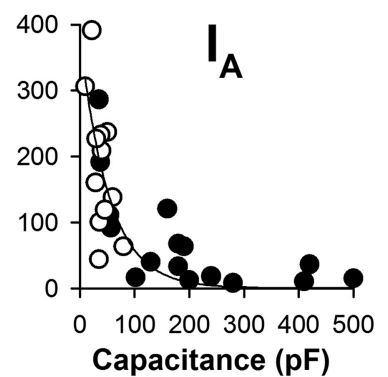

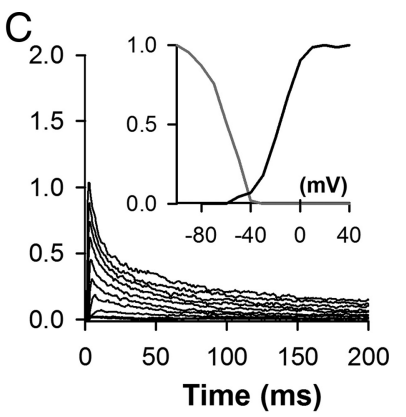

F

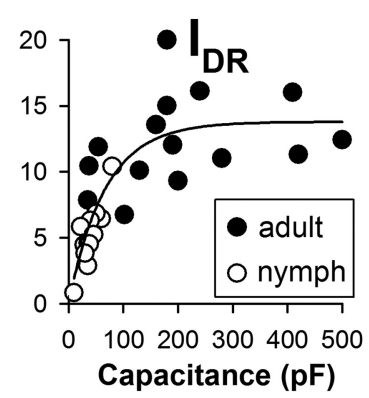

I

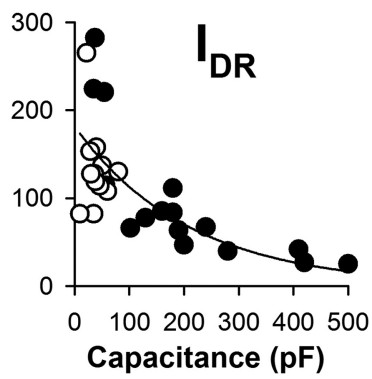

Figure 6. Potassium currents in stickinsect photoreceptors. Examples of the total $\mathrm{K}^{+}$current $(\boldsymbol{A}), I_{\mathrm{DR}}(\boldsymbol{B})$, and $I_{\mathrm{A}}(\boldsymbol{C}) \cdot \mathrm{I}_{\mathrm{DR}}$ was isolated from $I_{A}$ electrically; the currents were elicited by $500 \mathrm{~ms}$ pulses between -74 and $+36 \mathrm{mV}$ in $10 \mathrm{mV}$ increments from a HP of $-74 \mathrm{mV}$. Each testing step was preceded by a $1 \mathrm{~s}$ prepulse either to $-114 \mathrm{mV}$ (to fully recover $I_{A}$ ) or to $-36 \mathrm{mV}$ (to inactivate $I_{A}$ ); $I_{A}$ was then obtained by digital subtraction of the resultant traces; the first $2 \mathrm{~ms}$ of the current traces with capacitive transient were digitally removed. Inset in C shows examples of normalized voltage dependencies of activation and inactivation for $I_{A}$; steady-state inactivation recording protocol consisted of $2 \mathrm{~s}$ prepulses ranging from -100 to $0 \mathrm{mV}$ in $10 \mathrm{mV}$ increments followed by a $100 \mathrm{~ms}$ testing pulse to $+40 \mathrm{mV}$. D , Voltage dependencies of the average maximal conductance are shown for $I_{A}$ and $I_{D R}$ in nymphs and adults (closed circles, adult $I_{D R} ;$ open circles, nymph $I_{D R} ;$ closed triangles, adult $I_{A} ;$ open triangles, nymph $\left.I_{A}\right) ; I_{D R}$ was obtained at the end of $500 \mathrm{~ms}$ pulses. The data points were fitted with a Boltzmann function. $E, F$, Dependencies of the maximal $I_{A}$ and $I_{D R}$ conductances on capacitance; a scatter plot in $\boldsymbol{E}$ were fitted with an exponential function. $\boldsymbol{G}$, Voltage dependencies of the average maximal current density for the $I_{\mathrm{A}}$ and $I_{D R}$ in nymphs and adults. $H, I$, Correlations between capacitance and maximal current density for $I_{A}$ and $I_{D R}$.

delayed rectifier type $\mathrm{K}^{+}$current $\left(I_{\mathrm{DR}}\right)$ were found in stick insect photoreceptors:. The $I_{\mathrm{A}}$, but not the $I_{\mathrm{DR}}$, could be completely abolished by a $2 \mathrm{~s}$ inactivating prepulse to $-44 \mathrm{mV}$ (Fig. $6 A-C$ ), thus allowing experimental separation of these currents. Rapid inactivation of the $I_{\mathrm{A}}$ (Fig. $6 \mathrm{C}$, inset, gray trace, the halfinactivation potential was $-55.9 \pm 3.2 \mathrm{mV}$, average of 5 cells) implied that this current plays a rather limited role during continuous light responses in moderate and bright backgrounds, when membrane potential depolarizes to $-44 \mathrm{mV}$ or above. Differences were observed in the magnitudes but not kinetics of the $I_{\mathrm{A}}$ and $I_{\mathrm{DR}}$ between the nymphs and adults. The magnitudes of $\mathrm{K}^{+}$conductances (at $+36 \mathrm{mV}$ ) were: $6.3 \pm 0.9$ versus $7.5 \pm 1.0$ $\mathrm{nS}$ for the $I_{\mathrm{A}}$, and $5.2 \pm 0.7$ versus $11.9 \pm 0.9 \mathrm{nS}$ for the $I_{\mathrm{DR}}$ in the nymphs and adults, respectively (adults, 17 cells; nymphs, 12 cells; $p<0.001$ for the $\left.I_{\mathrm{DR}}\right)$. Note that in the nymphs, in contrast to the adults, the $I_{\mathrm{A}}$ was on average larger than the $I_{\mathrm{DR}}$ (Fig. $6 D$ ). No substantial difference in the kinetics of the $\mathrm{K}^{+}$currents was found between the nymphs and adults. For example, halfactivation potential $\left(V_{1 / 2}^{\mathrm{a}}\right)$ for the $I_{\mathrm{A}}$ was $-9.8 \pm 2.3 \mathrm{mV}$ in the nymphs and $-12.4 \pm 2.0 \mathrm{mV}$ in the adults; the corresponding values for the $I_{\mathrm{DR}}$ were $-21.3 \pm 1.7$ and $-23.2 \pm 1.9 \mathrm{mV}$. Having a significantly more depolarized $V_{1 / 2}^{\mathrm{a}}$ value for the $I_{\mathrm{A}}$ is quite unusual in insects (Wicher et al., 2001). For example, in fruit fly (Drosophila melanogaster) photoreceptors this relationship is reversed, with $I_{\mathrm{A}}$ activating at more hyperpolarized potentials than $I_{\mathrm{DR}}$ (Hardie, 1991; Niven et al., 2003a; Vähäsöyrinki et al., 2006). The voltage dependence of activation and inactivation of the $I_{\mathrm{A}}$ in the stick insect makes it appropriate for attenuation of the large voltage bumps in dim light. The role of the $I_{\mathrm{DR}}$, on the other hand, is probably the same as in photoreceptors of other insects, enabling transmission of faster signals and preventing excessive depolarization in brighter light by counteracting LIC (Weckström et al., 1991; Weckström and Laughlin, 1995; Vähäsöyrinki et al., 2006).

In Drosophila photoreceptors different ion channels may be expressed in different compartments: Shaker $\left(I_{\mathrm{A}}\right)$ channels -in the light-insensitive part of membrane (Rogero et al., 1997), light-activated channels - in the rhabdom (Hardie and Raghu, $2001)$, while the localization of Shab $\left(I_{\mathrm{DR}}\right)$ channels is unknown, 
although available evidence suggest that they are likely to be situated near the rhabdom (Hardie, 1991; Krause et al., 2008). Our data appear to fit this framework. It was not possible to detect any trend in $I_{\mathrm{A}}$ magnitude with increasing capacitance (Fig. $6 E$ ), but $I_{\mathrm{DR}}$ clearly increased with photoreceptor size (for the combined sample: $\rho=0.84, \rho^{2}=0.70$; for the $I_{\mathrm{DR}}$ in adults only: $\rho=0.49, \rho^{2}=0.24$ ) (Fig. $6 F$ ). On the other hand, densities of $I_{\mathrm{A}}$ and $I_{\mathrm{DR}}$ (obtained by dividing current magnitude by capacitance) were larger in the nymphs and decreased exponentially with photoreceptor size (Fig. 6G-I), implying a commensurate decrease in the relative area of light-insensitive membrane due to a corresponding increase in light-sensitive membrane. Note that the density of $I_{\mathrm{DR}}$ decreased with capacitance less sharply than the density of $I_{\mathrm{A}}$ (with a fourfold difference in the values of slope factors), consistent with the idea that $I_{\mathrm{DR}}$ channels are situated in close proximity to the microvillus, their number increasing along the enlarging microvilli with development. Interestingly, in immature photoreceptors from Drosophila pupae the Shaker channels manifest relatively late in development (pupal stage 11) and their density increases with development, while delayed rectifier $\mathrm{K}^{+}$ channels are found at the earliest stages (Hardie, 1991). Considering that one of the roles of $I_{\mathrm{A}}$ is the facilitation of communication between neurons (Hoffman et al., 1997), the observed differences between Drosophila pupae and stick insect nymphs might originate from the fact that the first instar stick insect retina is a fully functional organ, while the retina in Drosophila pupae undergoes rapid development and $I_{\mathrm{A}}$ channels might not be needed until connections of photoreceptors with second-order retinal neurons are established.

To address the relative changes in areas of light-insensitive and light-sensitive membrane with growth, we examined the LIC and its changes with development. To determine the maximal steady-state LIC magnitude, the LIC was evoked by $2 \mathrm{~s}$ light pulses in 10-fold intensity increments up to the point of saturation of the initial transient. The "steady-state" current at the end of each pulse was measured (Fig. $7 A, B$ ). Indeed, when maximal LICs were compared between the nymphs and adults, a 8.6-fold difference in the steadystate conductances emerged: $-1.0 \pm 0.2 \mathrm{nS}$ in the nymphs (11 cells) versus $-8.6 \pm 1.7 \mathrm{nS}$ ( 10 cells) in the adults (Fig. $7 A, B$ ). This increase in conductance was not accompanied by any significant increase in the LIC density $\left(-32.7 \pm 3.9 \mathrm{nS} \mathrm{nF}^{-1}\right.$ in the nymphs versus $-40.0 \pm 7.5 \mathrm{nS} \mathrm{nF}^{-1}$ in the adults), supporting the hypothesis that during the $\sim 5$-fold increase in membrane area with photoreceptor development a disproportional increase takes place in the lightsensitive membrane. Changes in the LIC with capacitance, and the absence of such changes in the density of the LIC, further illustrate this point (Fig. $7 C, D$ ).

\section{Developmental changes in photoreceptor performance in bright light}

Photoreceptor performance was studied using both white noisemodulated and naturalistic light stimulation over a large range of
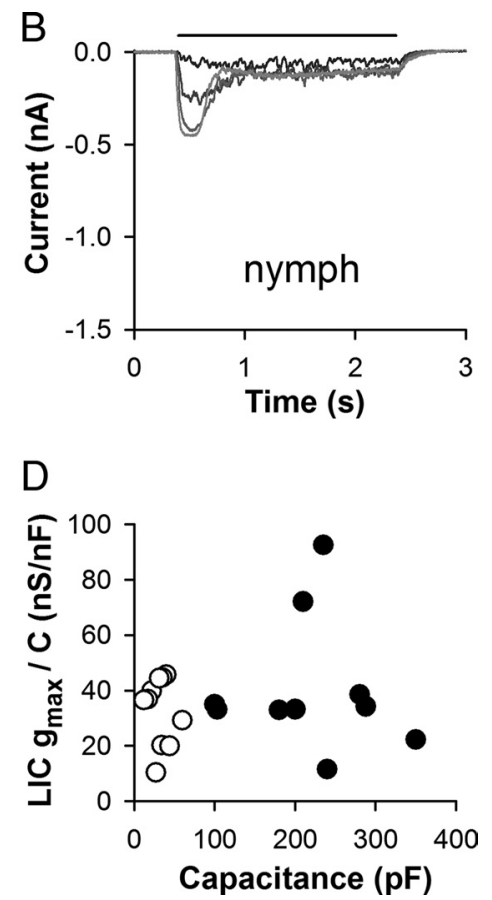

Fure 7. Light-induced currents in the stick insect. $A$, Macroscopic light-activated currents elicited by 4 s light pulses in 10 -fold to ranging from 300 to 300,000 effective photons $\mathrm{s}^{-1}$ in a photoreceptor from adult stick insect at a HP of $-74 \mathrm{mV}$ ge as in $\boldsymbol{A}$. C, D, Scatter plots show relationships between capacitance and maximal conductance and between capacitance and LIC in nymphs and adults.

light intensities, from the threshold of photoreceptor sensitivity (i.e., single photon signals) to intensities where transients were saturating. Figure $8 \mathrm{~A}$ demonstrates that in an adult stick insect, with increasing light intensity the transient and steady-state depolarization increased, the photoreceptor noise declined (as seen in the voltage responses before the onset of the white-noise contrast), and the contrast response changed, first gradually improving (best resolution, pink trace) and then rapidly deteriorating in brighter backgrounds (cyan and gray traces). Consistently with these changes, the IR of photoreceptors first gradually increased, reached a peak, and then fell sharply, both in the nymphs and adults (Fig. $8 B$ ). The IR decrease in brighter backgrounds is likely to reflect saturation of transduction units in bright light, because our experiments were performed on dissociated ommatidia, deprived of optical adaptation mechanisms (Laughlin, 1989; Roebroek and Stavenga, 1990; Meyer-Rochow and Keskinen, 2003). This agrees with a similar performance decrease found in whiteeyed flies (Howard et al., 1987).

Clear maxima of information rate $\left(\mathrm{IR}_{\max }\right)$ were observed in all photoreceptors without exception, indicating that $\mathrm{IR}_{\max }$ is likely to reflect an activity state of photoreceptor where they can respond equally robustly to both brighter and dimmer stimuli, that is, in the middle of its LIC range. To test this hypothesis, we compared plateau amplitudes of the LIC evoked at the light intensity corresponding to the $\mathrm{IR}_{\max }$ on one hand, and during saturating light on the other. Indeed, the magnitude of the LIC corresponding to the $\mathrm{IR}_{\max }$ was $55 \pm 4 \%$ of the maximal LIC induced by the brightest light (data from 5 cells). These results conform to the basic notion of information theory postulating that the signal variance as well as the entropy, and, therefore, the information content, is maximal when the system performs in the middle of its operating range.

Because of lower sensitivity to light, smaller LIC, and relatively large $\mathrm{K}^{+}$conductances, the same light stimulation yielded much 

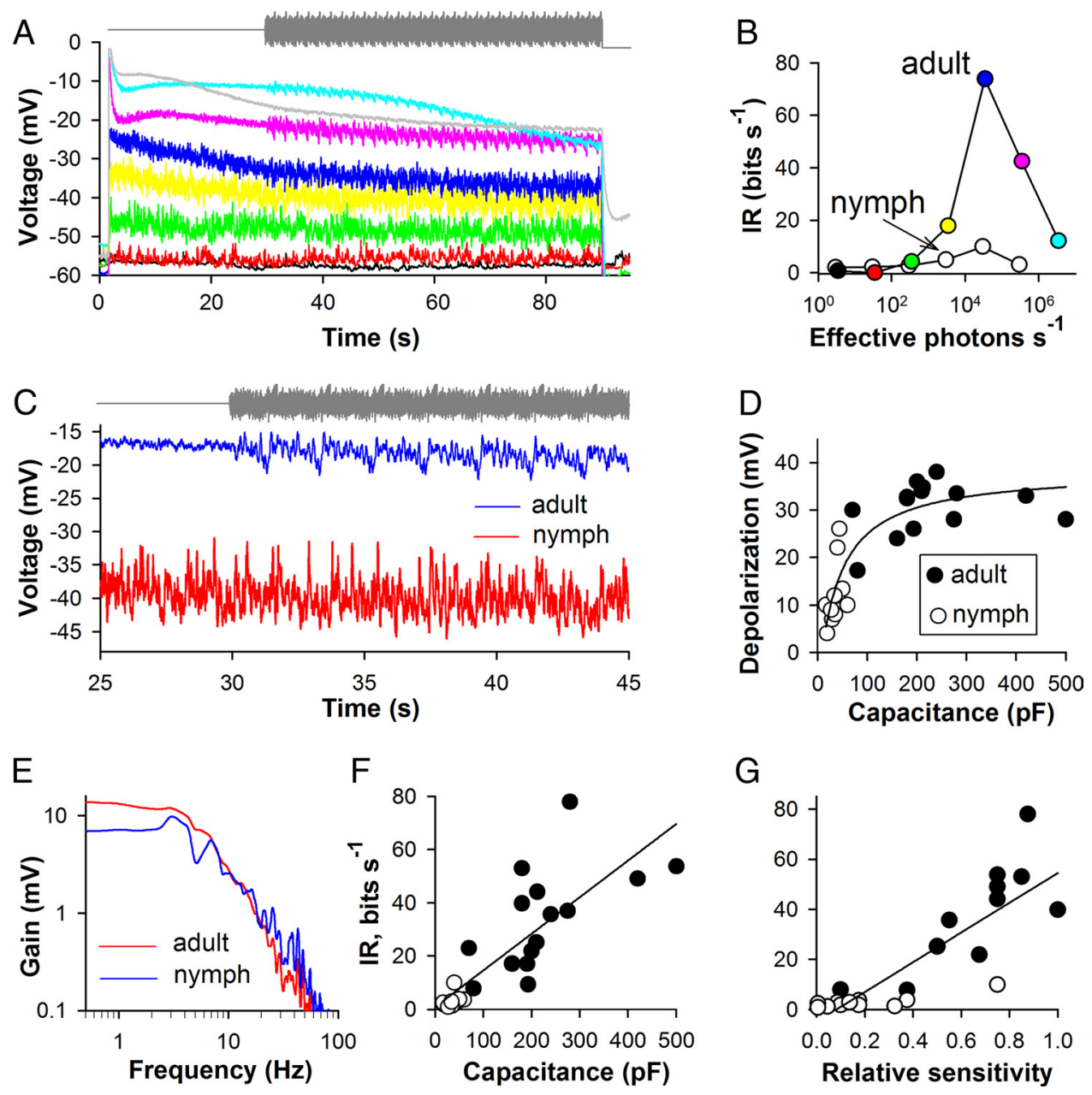

Figure 8. Signal processing in stick insect photoreceptors. $\boldsymbol{A}$, Voltage responses to a $60 \mathrm{~s}$ white noise modulated contrast with a preceding $30 \mathrm{~s}$ adapting prepulse (gray trace); intensity of the stimulus was increased from 3.5 effective photons $s^{-1}$ in 10 -fold increments from black to gray voltage trace. $\boldsymbol{B}$, Changes in information rate with increasing light intensity for the photoreceptor from $\boldsymbol{A}$ and for a highly performing nymph photoreceptor (open circles); color coding as in $\boldsymbol{A}$. C, Representative voltage responses to white noise in nymphs (red trace) and adults (blue trace) at a light level yielding the IR maximum. D, Correlation between photoreceptor capacitance and depolarization obtained as the difference between membrane potential at steady-state depolarization (at the light level yielding the IR maximum) and resting potential; data were fitted with a hyperbolic function. $\boldsymbol{E}$, Average contrast gain of voltage responses in nymphs and adults. $\boldsymbol{F}, \mathbf{G}$, Correlation between photoreceptor capacitance and $I R_{\max }(\boldsymbol{F})$ and between relative sensitivity to light and $I R_{\max }(\boldsymbol{G})$.

smaller depolarization in the nymphs. Figure $8 C$ compares representative recordings from nymphs and adults at light intensities, which elicited the voltage responses with the greatest IR in those cells. On average, such IR maximum responses had steadystate at $-22.4 \pm 1.6 \mathrm{mV}$ in the adults and at $-40 \pm 1.8 \mathrm{mV}$ in the nymphs, that is, photoreceptors were depolarized from resting potential by $30.3 \pm 2.0$ and $12.0 \pm 1.8 \mathrm{mV}$, correspondingly. The magnitude of depolarization strongly correlated with cell capacitance (Fig. $8 D, \rho=0.88, \rho^{2}=0.78$, data from 25 cells) when a hyperbolic function, describing self-shunting of receptor potential (Laughlin, 1989), was fitted to the data. This once again indicated that in the stick insect the whole-cell capacitance can serve as a proxy for the cell membrane, dominated by the microvilli, and thereby also for the size of the light-activated conductance. Stick insect photoreceptors demonstrated relatively large gain in the lower frequency range with a low corner frequency, which would facilitate greater sensitivity at the expense of membrane speed, and be arguably suitable for dim vision. Adult photoreceptors were characterized by larger gain at low frequencies, $14.8 \pm$ $1.6 \mathrm{mV}$, versus $8.9 \pm 1.0 \mathrm{mV}$ in the nymphs $(p<0.01$, Fig. $8 E)$. The corner frequencies of the frequency response functions, $\mathrm{T}(\mathrm{f})$, were obtained by fitting data with a Lorenzian function, yielding
$5.1 \pm 0.3 \mathrm{~Hz}$ for the adults (11 cells) and $7.4 \pm 0.7 \mathrm{~Hz}$ for the nymphs ( 12 cells) $(p<0.01)$, indicating a slightly faster response speed in nymph photoreceptors, which is consistent with our observations in dim light (Fig. 4B).

In the adults, the $\mathrm{IR}_{\max }$ was more than 10 -fold higher than in the nymphs, $34.1 \pm 5.0$ versus $2.9 \pm 0.7$ bits s $^{-1}$. Apparently, one of the reasons for this difference was large photon noise (because of larger bumps) in the recordings from nymph photoreceptors (Fig. 8C). In adults, this noise was attenuated with increasing depolarization (see noisiness of light responses to steady light during first $30 \mathrm{~s}$ of the stimulus in Fig. $8 A$ ). In addition, important strong correlations were found between capacitance and information rate (Fig. $8 F, \rho=0.90, \rho^{2}=0.81$, data from 27 cells), and between sensitivity to light and information rate (Fig. $8 G, \rho=$ $0.87, \rho^{2}=0.77$, data from 22 cells), indicating an obvious fact that larger and more sensitive photoreceptors with larger number of microvilli performed better than their smaller and less sensitive counterparts. Importantly, in 14 of 17 photoreceptors of adult stick insects the $\mathrm{IR}_{\max }$ values were found at the same light level, which roughly matched light emission from cloudy moonless evening sky, indicating that photoreceptors of adult stick insects may be evolutionarily optimized for vision in dim environments 
and that in the absence of optical adaptation mechanisms their performance would gradually deteriorate in brighter environments. In three remaining experiments, one cell demonstrated the $\mathrm{IR}_{\max }$ in dimmer and two in brighter light. The $\mathrm{IR}_{\max }$ values in the nymphs appeared to be more broadly distributed, but because of very low information rates the IR peaks were much less pronounced.

\section{Saturation of nymph responses by white-noise stimulation}

To investigate whether nymph photoreceptors process naturalisticlike stimulation as poorly as they do white noise, responses of nymphs and adults to a naturalistic stimulus (Fig. 9A) were compared. A much smaller difference in information rate was found between nymphs and adults (Fig. 9A), suggesting that nymphs can actually see much better than expected on the basis of experiments with white-noise contrasts (the information rates for these voltage responses were estimated using a novel mutual information method; Takalo et al., 2011).

The observed discrepancy can be explained by the differences in the structure of white-noise and naturalistic stimuli: in the white-noise stimulus the power is distributed equally across the spectrum, while the naturalistic stimulus is characterized by an $\sim 1$ /f power distribution with concomitant concentration of spectral power in the low-frequency region. Moreover, the very nature of white-noise stimulation requires a non-zero mean illumination level from which both positive and negative contrasts could be elicited in equal measure. In our experiments, to maximize the energy output, the mean light level of the white-noise stimulus was in the middle of the LED range with contrast oscillations spanning the entire LED range, from zero to maximum. On the other hand, the naturalistic stimulus had on average a sixfold lower mean light intensity.

Because microvilli have a relatively slow recovery time (Song et al., 2012), and because nymph photoreceptors were characterized by smaller light-sensitive membrane area than photoreceptors from adults, poor performance of nymph photoreceptors in response to whitenoise stimulation could possibly result from saturation of the majority of nymph microvilli by the previously absorbed photons so that their collective output mostly encoded the light level rather than its modulation, this situation being equivalent to having too few sampling units with too low sampling rate to capture fast events. In contrast, adult photoreceptors with much larger rhabdoms might have a larger pool of non-inactivated microvilli to respond to light changes $<20 \mathrm{~Hz}$. To test this hypothesis, we additionally recorded responses to two "white-noise" stimuli with a cutoff frequency of $15 \mathrm{~Hz}$ (two-times greater than the average stick insect photoreceptor $f_{3 \mathrm{~dB}}$ ) obtained by low-pass filtering of the original white-noise stimulus (with a $f_{3 \mathrm{~dB}}$ of $250 \mathrm{~Hz}$ and mean contrast of 0.31 ; Fig. $10 \mathrm{~A}, B$ ). For one of the $15 \mathrm{~Hz}$ stimuli the light modulation amplitude was multiplied fourfold, yielding a 16 -fold increase in power density in the $0-15 \mathrm{~Hz}$ bandwidth and thereby correcting the mean contrast by a factor of four from 0.08 to 0.35
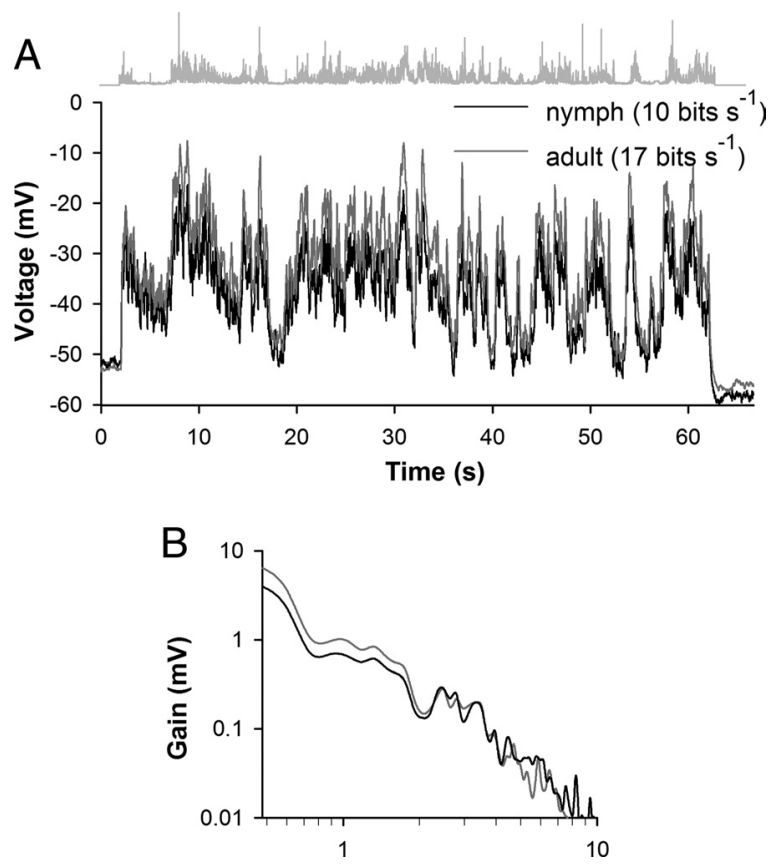

Figure 9. Responses to naturalistic stimulation. $A$, Voltage responses were elicited by a $60 \mathrm{~s}$ naturalistic contrast at 3000 effective photons $s^{-1}$ for the nymph photoreceptor (dark gray trace) and 4000 effective photons $s^{-1}$ for the adult photoreceptor (black trace). B, Contrast gain is shown for the corresponding voltage responses.
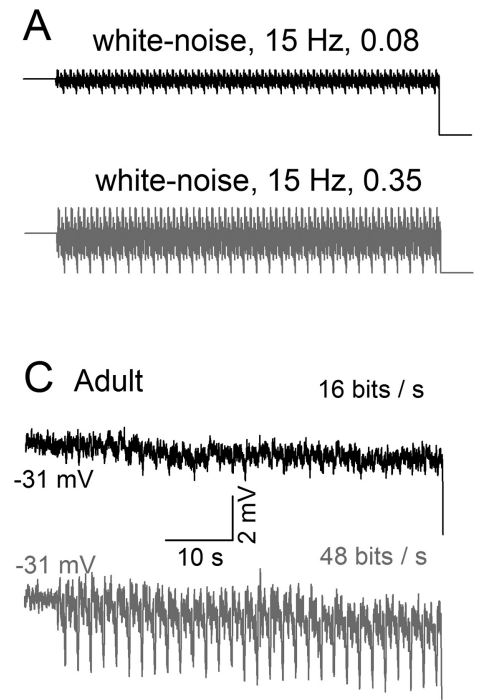
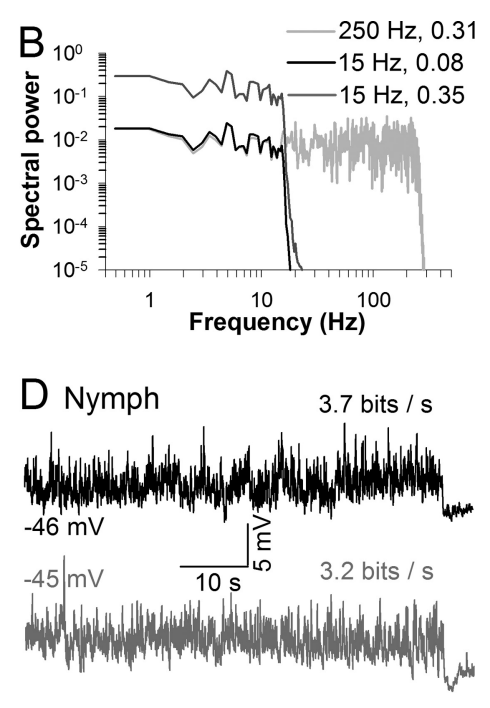

Figure 10. Structure of white-noise stimulus and information rate. $\boldsymbol{A}$, The white-noise stimulus used throughout the study (black trace, mean contrast of 0.31 ; also see insets in Fig. $2 A$ and $8 A$ ) was low-pass filtered to produce a stimulus with a cutoff frequency of $15 \mathrm{~Hz}$ and mean contrast of 0.08 (black trace); another stimulus was made from it by multiplying contrast by a factor of four (dark gray trace, mean contrast of 0.35 ). B, Power spectra of the three stimuli. Gray trace represents the original white-noise stimulus. $\boldsymbol{C}, \boldsymbol{D}$, A photoreceptor from an adult stick insect responded with increased gain to the magnified $15 \mathrm{~Hz}$ stimulus $(\boldsymbol{C})$, while a nymph photoreceptor demonstrated no difference $(\boldsymbol{D})$. Voltages refer to the mean potentials during responses.

(15 Hz, 0.35, Fig. 10A,B). If the immature nymph photoreceptors were saturated by the mean light level of the white-noise stimulus, then the increase in stimulus power in the visible part of the spectrum would not result in increased photoreceptor response signal. Figure 10, $C$ and $D$, demonstrates that this was indeed the case: stimulation with a contrast-corrected whitenoise dramatically increased contrast response and information rate in adults but not in the nymphs. 

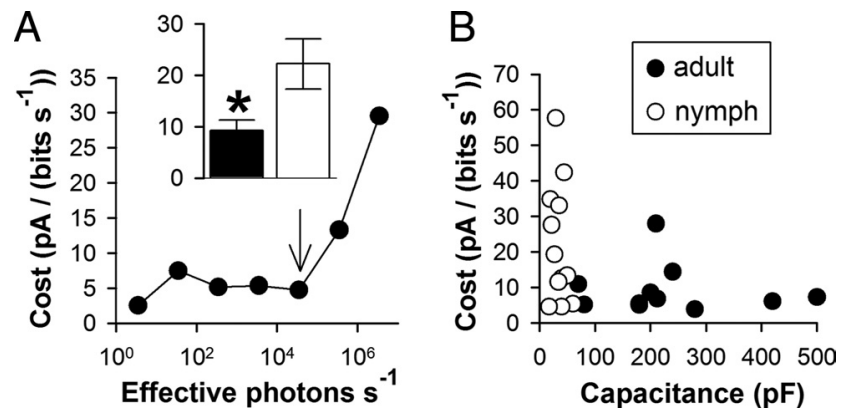

Figure 11. Metabolic cost of signaling. $\boldsymbol{A}$, An example of changes in the magnitude of total $\mathrm{K}^{+}$current per unit of information (for the photoreceptor from Fig. $8 A, B$ ). Arrow indicates $\mathbb{R}_{\max }$ i inset shows average values for the nymphs and adults at $I R_{\max }$ illumination level. ${ }^{*} p<$ 0.05 . $B$, Dependence of the magnitude of $\mathrm{K}^{+}$current per unit of information on the photoreceptor capacitance at the light level yielding the $\mathbb{R}_{\max }$.

Therefore, the particular structure of white-noise stimuli (the presence of a mean light level) resulted in underestimation of information capacity in stick insect photoreceptors, especially in nymphs. This also compromised comparison of information processing between nymphs and adults as it compared a nearly fully saturated system (the nymph photoreceptor) to one which still has an approximately sufficient pool of non-inactivated microvilli to respond to light changes in the low-frequency region (the adult photoreceptor). Although the use of naturalistic stimulation appears to be a better method of determining information rates of adult and nymph photoreceptors, it cannot necessarily ensure a reliable comparison of different systems as even extensive modifications of naturalistic stimuli in a previous study may fail to provide consistent readings of maximal information rate, even under the same experimental conditions (Juusola and de Polavieja, 2003).

\section{Metabolic costs of information}

In several insect species, the metabolic cost of vision increases with illumination due to larger depolarization, but the cost of information per bit decreases as photoreceptor performance improves even faster as a function of illumination (Laughlin et al., 1998; Niven et al., 2003a,b, 2007). In contrast, stick insect photoreceptors demonstrated a clear peak of IR with an abrupt decrease at brighter backgrounds. This occurred without a proportional reduction in the level of photoreceptor depolarization (Fig. 8A). We addressed the metabolic consequences of these findings by calculating the magnitude of the total voltage-activated $\mathrm{K}^{+}$current at the end of $500 \mathrm{~ms}$ pulses at steady-state depolarization level and dividing this by the corresponding information rate. Although a full photoreceptor model would be required for accurate estimation of the metabolic costs, the $\mathrm{K}^{+}$current can be used as an approximate proxy for the costs of maintaining a steady-state level of depolarization when other types of voltage activated conductances are absent (Niven et al., 2003a). As expected, a sharp rise in the size of $\mathrm{K}^{+}$current per unit of information was found in bright backgrounds (Fig. 11A). An inset in the Figure $11 A$ presents the average $\mathrm{K}^{+}$current per bits $\mathrm{s}^{-1}$ at the $\mathrm{IR}_{\max }$ light level for nymphs and adults, and Figure $11 B$ demonstrates a scatter plot for the entire set of data. These results imply that information processing in stick insect photoreceptors improves over the course of postembryonic development and information becomes metabolically less expensive up to the mean light intensity of $\sim 10^{4}$ effective photons $\mathrm{s}^{-1}$.

\section{Discussion}

In this study we examined electrophysiological properties of stick insect photoreceptors for the first time. We also provided a comparative analysis of performance for two developmental stages, first instar nymphs and adults. This appears to be the first study comparing electrical properties and performance of photoreceptors at different developmental stages in hemimetabolous insects (with incomplete metamorphosis). The only other study touching this issue has been a comparison of properties of voltageactivated $\mathrm{K}^{+}$conductances in the photoreceptors of nymph and adult locusts (Weckström, 1994), where no substantial differences were found between the experimental groups. Another important feature of this study is that it was performed on dissociated photoreceptors, deprived of extracellular or optical adaptation mechanisms, which would otherwise modulate the photon flux reaching photoreceptors. In dissociated photoreceptors we bypass the intraommatidial mechanisms of light attenuation, such as migration of pigment granules inside the photoreceptor or migration of retinula cells themselves (Laughlin, 1989; Meyer-Rochow and Keskinen, 2003), because these mechanisms attenuate the light entering the rhabdom through optics and do not essentially reduce light from the side of the dissociated ommatidia on the bottom of the recording chamber.

In the stick insect the visually guided behavior of nymphs appears to be essential for the fitness of the species. Previous studies suggest that stick insects are able to distinguish vertical patterns from slanted and horizontal ones (Godden, 1973) and to discriminate between differently aligned tree-like shapes (Frantsevich and Frantsevich, 1996; Meyer-Rochow and Keskinen, 2003). The dayactive small-sized Carausius young are responsible for expanding the species range by finding food plants away from the place of hatching. Similar behavior of slowly moving large and vulnerable adults could be too costly even during night time, despite the good visual performance of the mature photoreceptors. Our results indicate that developmental changes in the biophysical properties of photoreceptors correspond to the changes in the visual behavior of the animal. This correlation may be causal, in the sense that changes in the photoreceptor properties have adapted to the diurnal and expanding lifestyle of the nymphs and the nocturnal, slow-moving behavior of the adults, although we cannot pin-point the cellular mechanisms behind steering these adaptations during development on the basis of the present results. Surprisingly, most of the observed differences in photoreceptor properties between nymphs and adults appear to be related to growth and maturation of photoreceptors, while only two-larger current quantum bumps (Fig. $4 C$ ) and faster light adaptation (Fig. $2 B, C$ ) in the nymphscould be regarded as specific adaptations to diurnal lifestyle. The differences between nymphs and adults can be separated into five categories: facilitating or impeding diurnal vision, facilitating or impeding nocturnal vision, and those improving the photoreceptor performance generally. In the following we examine the available evidence in this context.

In contrast to adults, nymph photoreceptors demonstrated smaller capacitance, lower sensitivity to light, larger quantum bumps, larger and faster elementary voltage responses, more pronounced peak-to-plateau transition during voltage responses in bright light, and larger $I_{\mathrm{A}}$ current than $I_{\mathrm{DR}}$ (the differences are summarized in Table 1). Smaller capacitance increases the speed of photoreceptor membrane (as evidenced by higher values of the $f_{3 \mathrm{~dB}}$ in the nymphs), facilitating information processing in bright light. Lower sensitivity to light clearly resulted from the relatively small 
Table 1. Differences between photoreceptors from nymphs and adults

\begin{tabular}{|c|c|c|}
\hline Parameter & Nymphs & Adults \\
\hline Capacitance (pF) & $37 \pm 21^{\S}$ & $212 \pm 104^{\S}$ \\
\hline Resting potential (mV) & $-51.8 \pm 1.7$ & $-53.0 \pm 1.3$ \\
\hline$R_{\text {in }}$ at $-54 \mathrm{mV}(\mathrm{M} \Omega)$ & $1390 \pm 170$ & $620 \pm 90^{* *}$ \\
\hline$f_{3 \mathrm{~dB}}$ at $-54 \mathrm{mV}(\mathrm{Hz})$ & 4.0 & 1.9 \\
\hline Leak (nS) & $0.7 \pm 0.1$ & $1.6 \pm 0.3^{* *}$ \\
\hline Voltage bump (mV) & $5.1 \pm 1.0$ & $1.9 \pm 0.2^{* *}$ \\
\hline Current bump (pA) & $26.9 \pm 3.4$ & $19.1 \pm 1.7^{*}$ \\
\hline$I_{\mathrm{DR}} g_{\max }$ at $+36 \mathrm{mV}(\mathrm{nS})$ & $5.2 \pm 0.7$ & $11.9 \pm 0.9^{* *}$ \\
\hline $\mathrm{LIC} g_{\max }(\mathrm{nS})$ & $-1.0 \pm 0.2$ & $-8.6 \pm 1.7^{* *}$ \\
\hline $\mathbb{I R}_{\max }\left(\right.$ bits $^{-1}$ ) & $2.9 \pm 0.7$ & $39 \pm 6^{* *}$ \\
\hline$f_{3 \mathrm{~dB}}(\mathrm{~Hz})^{\dagger}$ & $7.4 \pm 0.7$ & $5.1 \pm 0.3^{*}$ \\
\hline Low-frequency gain $(\mathrm{mV})^{\dagger}$ & $8.9 \pm 1.0$ & $14.8 \pm 1.6^{* *}$ \\
\hline Depolarization $(\mathrm{mV})^{\dagger}$ & $12.0 \pm 1.8$ & $31.5 \pm 2.1^{* *}$ \\
\hline
\end{tabular}

rhabdom of the newly emerged nymphs, and while not directly linked to seeing in daylight, it makes seeing in dim light more difficult for the animal and thus could promote the diurnal activity of the nymphs.

The reason for nymphs having bigger quantum bumps than adults is not known. Functionally, however, large bumps are likely to represent an adaptation that improves the SNR under conditions of relatively low photon absorption rate, in dim light or when the photoreceptor's sensitivity to light is low. Nymph photoreceptors demonstrated $>2$-fold greater input resistance and fivefold smaller capacitance than adult photoreceptors. This would lead to increased noise from all sources, due to a greater gain and a faster membrane [note the strong inverse dependence of voltage bump magnitude on capacitance (Fig. 4D)]. To compensate for noisier responses and produce the SNR comparable to that in adults in continuous signaling, an increase in the voltage bump size at least proportional to the increase in noise is necessary. This can be achieved by only a greater than proportional increase in the current bump magnitude, because self-shunting of receptor potential disproportionally suppresses the amplitude of depolarizing voltage events.

Compared with adults, nymphs demonstrated $I_{\mathrm{A}}$ of a similar magnitude and a much smaller $I_{\mathrm{DR}}$. The role of $I_{\mathrm{A}}$ in the stick insect was most likely the attenuation of large isolated voltage responses in dim light. Thus it was different from the role of $I_{\mathrm{A}}$ in Drosophila photoreceptors, which generate much smaller voltage bumps (Juusola and Hardie, 2001; Niven et al., 2003b). $I_{\mathrm{DR}}$ was obviously responsible for regulating membrane gain and depolarization level, as in fly photoreceptors (Weckström et al., 1991; Weckström and Laughlin, 1995; Vähäsöyrinki et al., 2006). In the nymphs $I_{\mathrm{DR}}$ was on average twofold smaller than in the adults, but this did not result in an excessively high depolarization in steady light because the LIC in the nymphs was 8.6-fold smaller than in the adults (Fig. 8C). However, having a smaller $I_{\mathrm{DR}}$ was instrumental for increasing the gain of voltage responses as shown in Figure 9, which illustrates responses of a typical nymph and adult photoreceptors to a naturalistic contrast. In the recordings shown, the photoreceptor from an adult stick insect had a capacitance of $200 \mathrm{pF}$, the steady-state LIC conductance of $3.5 \mathrm{nS}$ (at the light level of $\mathrm{IR}_{\max }$ ), the $I_{\mathrm{DR}} g_{\max }$ of $14.6 \mathrm{nS}$, and the mutual information rate of 15 bits s $^{-1}$. The nymph photoreceptor had a capacitance of $44 \mathrm{pF}$, the LIC conductance of $0.9 \mathrm{nS}$, the $I_{\mathrm{DR}}$ $g_{\max }$ of $4.1 \mathrm{nS}$, and the mutual information rate of 10 bits s $^{-1}$. The nymph photoreceptor demonstrated contrast resolution on par with the adult cell, probably as a result of the relatively high gain due to the smaller $\mathrm{K}^{+}$conductance, which substantially attenuated the fourfold difference in the LIC (Fig. 9B). Note that when gain integrals were obtained in the frequency range from 0.5 to $10 \mathrm{~Hz}$, only a $22 \%$ difference emerged between the nymph and adult photoreceptors.

In adult photoreceptors, on the other hand, the higher capacitance, greater light sensitivity, larger area of light-absorbing membrane, and better information processing facilitated nocturnal lifestyle. Two other findings, the presence of a pronounced peak of the IR and the concomitant sharp increase in the metabolic cost of vision in more illuminated backgrounds, can be argued to impede the diurnal behavior of adult stick insects. While the IR peak itself reflects the light intensity where saturation of the transduction units in photoreceptors is approached (Howard et al., 1987), the ecological relevance of this may be disputable, as the mechanisms of light attenuation present in the intact eye (but not in our experimental setting) would reduce the incoming light flux, possibly as much as by two to three decades (Roebroek and Stavenga, 1990), and correspondingly expand the intensity range of vision. However, this would not abolish the peak itself, instead transforming it into a sloping plateau at higher light intensities. Considering that in the majority of photoreceptors (in 14 of 17) the peak was observed in quite dim backgrounds (roughly matching irradiation from cloudy moonless evening sky), where light adaptation mechanisms are unlikely to be used to the full, this shift would probably be small.

During the day, adult stick insects enter the light-induced "thanatos" state, assuming a stick posture (Bullock and Horridge, 1965). This behavior appears to be not a circadian adaptation per se; instead, it is triggered by an increase in illumination and could be the single most important aspect determining the nocturnal behavior of adults. The neural mechanisms of photoinhibition are not known, although its properties have been studied and the principal role of the compound eye has been established. Photoinhibition depends on the amount of light perceived through the compound eyes (Godden and Goldsmith, 1972; Godden, 1972). Its induction requires excitation of the entire eye or a large portion of the eye, but not of a specific visual field or region (Godden and Goldsmith, 1972). We tested the effects of sudden increase in illumination on the activity of first instar nymphs but found none. While the most likely reason for that is the presumed immaturity of the involved neural circuitry, it is still feasible that the small size and low sensitivity of the first instar nymph eyes might play a role in the lack of the behavioral reaction. Interestingly, the light intensity at which we usually observed the $\mathrm{IR}_{\max }$ in adults seems to approximately match the intensity, above which the arousal from the diurnal thanatosis is inhibited (Godden and Goldsmith, 1972).

Overall, the evidence presented here demonstrates that the growth of the compound eye in the stick insect is associated with profound changes in the electrical properties of photoreceptors. This, together with the developing behavior of thanatosis, facilitates the observed shift from the diurnal to nocturnal lifestyle, changing the light level where photoreceptors function optimally. Determining the precise timing of this behavioral shift in relation to the changes in the photoreceptor biophysics and a possible role of these changes in the development of the thanatosis, as well as electrophysiological characterization of the processes in the retina accompanying the thanatosis, requires further study.

\section{References}

Bullock TH, Horridge GA (1965) Structure and function in the nervous systems of invertebrates, vol 1. San Francisco: WH Freeman and Co.

Faivre O, Juusola M (2008) Visual coding in locust photoreceptors. PLoS One 3:e2173. CrossRef Medline

Frantsevich L, Frantsevich L (1996) Space constancy in form perception by the stick insect. Naturwissenschaften 83:323-324. CrossRef 
Frederiksen R, Wcislo WT, Warrant EJ (2008) Visual reliability and information rate in the retina of a nocturnal bee. Curr Biol 18:349-353. CrossRef Medline

Godden D, Goldsmith TH (1972) Photoinhibition of arousal in the stick insect Carausius. J Comp Physiol A Neuroethol Sens Neural Behav Physiol 76:135-145.

Godden DH (1972) The motor innervation of the leg musculature and motor output during thanatosis in the stick insect Carausius morosus Br. J Comp Physiol A Neuroethol Sens Neural Behav Physiol 80:201-225. CrossRef

Godden DH (1973) A re-examination of circadian rhythmicity in Carausius morosus. J Insect Physiol 19:1377-1386. CrossRef

Hardie RC (1991) Voltage-sensitive potassium channels in Drosophila photoreceptors. J Neurosci 11:3079-3095. Medline

Hardie RC, Raghu P (2001) Visual transduction in Drosophila. Nature 413: 186-193. CrossRef Medline

Hardie RC, Voss D, Pongs O, Laughlin SB (1991) Novel potassium channels encoded by the Shaker locus in Drosophila photoreceptors. Neuron 6:477-486. CrossRef Medline

Heimonen K, Salmela I, Kontiokari P, Weckström M (2006) Large functional variability in cockroach photoreceptors: optimization to low light levels. J Neurosci 26:13454-13462. CrossRef Medline

Hoffman DA, Magee JC, Colbert CM, Johnston D (1997) K+ channel regulation of signal propagation in dendrites of hippocampal pyramidal neurons. Nature 387:869-875. CrossRef Medline

Howard J, Blakeslee B, Laughlin SB (1987) The intracellular pupil mechanism and photoreceptor signal: noise ratios in the fly Lucilia cuprina. Proc R Soc Lond B Biol Sci 231:415-435. CrossRef Medline

Juusola M, de Polavieja GG (2003) The rate of information transfer of naturalistic stimulation by graded potentials. J Gen Physiol 122:191-206. CrossRef Medline

Juusola M, Hardie RC (2001) Light adaptation in Drosophila photoreceptors: I. Response dynamics and signaling efficiency at 25 degrees C. J Gen Physiol 117:3-25. Medline

Keskinen E, Takaku Y, Meyer-Rochow VB, Hariyama T (2002) Postembryonic eye growth in the seashore isopod Ligia exotica (Crustacea, Isopoda). Biol Bull 202:223-231. CrossRef Medline

Kouvalainen E, Weckström M, Juusola M (1994) A method for determining photoreceptor signal-to-noise ratio in the time and frequency domains with a pseudorandom stimulus. Vis Neurosci 11:1221-1225. CrossRef Medline

Krause Y, Krause S, Huang J, Liu CH, Hardie RC, Weckström M (2008) Light-dependent modulation of Shab channels via phosphoinositide depletion in Drosophila photoreceptors. Neuron 59:596-607. CrossRef Medline

Laughlin SB (1989) The role of sensory adaptation in the retina. J Exp Biol 146:39-62. Medline

Laughlin SB (1996) Matched filtering by a photoreceptor membrane. Vision Res 36:1529-1541. CrossRef Medline

Laughlin SB, de Ruyter van Steveninck RR, Anderson JC (1998) The metabolic cost of neural information. Nat Neurosci 1:36-41. CrossRef Medline

Machens CK, Gollisch T, Kolesnikova O, Herz AV (2005) Testing the efficiency of sensory coding with optimal stimulus ensembles. Neuron 47 : 447-456. CrossRef Medline
Meyer-Rochow VB, Keskinen E (2003) Post-embryonic photoreceptor development and dark/light adaptation in the stick insect Carausius morosus (Phasmida, Phasmatidae). Appl Entomol Zool 38:281-291. CrossRef

Myers JL, Well AD (2003) Research design and statistical analysis, Ed 2. Mahwah, NJ: Lawrence Erlbaum and Associates.

Niven JE, Vahasoyrinki M, Juusola M (2003a) Shaker K(+)-channels are predicted to reduce the metabolic cost of neural information in Drosophila photoreceptors. Proc Biol Sci 270 Suppl 1:S58-S61.

Niven JE, Vähäsöyrinki M, Kauranen M, Hardie RC, Juusola M, Weckström M (2003b) The contribution of Shaker K+ channels to the information capacity of Drosophila photoreceptors. Nature 421:630-634. CrossRef Medline

Niven JE, Anderson JC, Laughlin SB (2007) Fly photoreceptors demonstrate energy-information trade-offs in neural coding. PLoS Biol 5:e116. CrossRef Medline

Porter ML, Zhang Y, Desai S, Caldwell RL, Cronin TW (2010) Evolution of anatomical and physiological specialization in the compound eyes of stomatopod crustaceans. J Exp Biol 213:3473-3486. CrossRef Medline

Roebroek JG, Stavenga DG (1990) On the effective optical density of the pupil mechanism in fly photoreceptors. Vision Res 30:1235-1242. CrossRef Medline

Rogero O, Hämmerle B, Tejedor FJ (1997) Diverse expression and distribution of Shaker potassium channels during the development of the Drosophila nervous system. J Neurosci 17:5108-5118. Medline

Song Z, Postma M, Billings SA, Coca D, Hardie RC, Juusola M (2012) Stochastic, adaptive sampling of information by microvilli in fly photoreceptors. Curr Biol 22:1371-1380. CrossRef Medline

Takalo J, Ignatova I, Weckström M, Vähäsöyrinki M (2011) A novel estimator for the rate of information transfer by continuous signals. PLoS One 6:e18792. CrossRef Medline

Tomioka K, Chiba Y (1982) Post-embryonic development of circadian rhythm in the cricket, Gryllus bimaculatus: a rhythm reversal. J Comp Physiol A Neuroethol Sens Neural Behav Physiol 147:299-304. CrossRef

Vähäsöyrinki M, Niven JE, Hardie RC, Weckström M, Juusola M (2006) Robustness of neural coding in Drosophila photoreceptors in the absence of slow delayed rectifier K+ channels. J Neurosci 26:2652-2660. CrossRef Medline

van Hateren JH, van der Schaaf A (1998) Independent component filters of natural images compared with simple cells in primary visual cortex. Proc Biol Sci 265:359-366. CrossRef Medline

Warrant E, Dacke M (2011) Vision and visual navigation in nocturnal insects. Annu Rev Entomol 56:239-254. CrossRef Medline

Weckström M (1994) Voltage-activated outward currents in adult and nymphal locust photoreceptors. J Comp Physiol A Neuroethol Sens Neural Behav Physiol 174:795-801.

Weckström M, Laughlin SB (1995) Visual ecology and voltage-gated ion channels in insect photoreceptors. Trends Neurosci 18:17-21. CrossRef Medline

Weckström M, Hardie RC, Laughlin SB (1991) Voltage-activated potassium channels in blowfly photoreceptors and their role in light adaptation. J Physiol 440:635-657. Medline

Wicher D, Walther C, Wicher C (2001) Non-synaptic ion channels in insects-basic properties of currents and their modulation in neurons and skeletal muscles. Prog Neurobiol 64:431-525. CrossRef Medline 